ScIDice

\section{Evaluation of Oral Hygiene Status in Patients with Shallow Vestibular Depth in A Hospital Setting - A Retrospective Analysis}

\section{International Journal of Dentistry and Oral Science (IJDOS) ISSN: 2377-8075}

Lakshya Rani.S ${ }^{1}$, Jeevitha ${ }^{2 *}$, G.Maragathavalli ${ }^{3}$

${ }^{1}$ Saveetha Dental College And Hospitals, Saveetha Institute Of Medical and Technical Sciences, Saveetha University, Chennai,600050, India.

${ }^{2}$ Senior Lecturer, Department of Periodontics, Saveetha Dental College and Hospitals, Saveetha Institute Of Medical And Technical Sciences, Saveetha University, Chennai, India.

${ }^{3}$ Professor, Department of Oral Medicine, Saveetha Dental College and Hospitals, Saveetha Institute Of Medical And Technical Sciences, Saveetha University, Chennai, India.

\title{
Abstract
}

Vestibular depth and attached gingiva is an important factor affecting periodontal health which is associated with efficient plaque removal around the gingival margin, improves aesthetics and reduces inflammation around a restored tooth. The role of width of attached gingiva and vestibular depth on gingival health and oral hygiene is inconclusive. The aim of the study is to evaluate the oral hygiene status in patients with shallow vestibular depth. This is a retrospective study conducted in a University hospital setting. The data with a total of 86000 patients records between June 2019 to March 2020 were taken and after fulfillment of inclusion and exclusion criteria, a final sample of 14 patients were considered who had shallow vestibular depth. The data regarding the age, gender and oral hygiene index- simplified of the patients were retrieved from patients records and analysed. The data was tabulated and statistically analysed. It is observed that the majority of the study population were found to have fair $(57.1 \%)$ oral hygiene status. The study showed no significant association of oral hygiene with age and gender in the presence of shallow vestibular depth $(\mathrm{p}>0.05)$.

Keywords: Oral Health; Oral Hygiene; Periodontal; Shallow Vestibular Depth.

\section{Introduction}

Oral health is considered as the quality of health that enables an individual to socialize easily without any active disease, discomfort or embarrassment which impacts general well being [1]. One of the major public health problems is oral diseases, which has higher prevalence and significant social impact [2]. To improve on oral health in the community, it is essential to have oral health related knowledge. Good oral hygiene has shown to contribute greatly to the prevention of oral diseases $[2,3]$.

Periodontal practice not only emphasizes biological and functional problems that affect the periodontium but also focuses on improving aesthetic appearance due to recent advances on periodontal therapy [3]. Gingival recession is defined as exposure of the root surface by the apical migration of junctional epithelium which causes poor aesthetic appearance, root hypersensitivity and root caries [4]. Shallow vestibule along with inadequate width of attached gingiva is a common cause of gingival recession and it is a very common clinical finding in the front region of the lower jaw [5].

Shallow vestibule, gingival recession, and aberrant frenum which causes mucogingival problems, several independent and effective surgical procedures have been developed. The depth of vestibule and the width of the attached gingiva can be increased in a single visit by vestibular deepening procedure [6]. The vestibular depth is defined either as the distance between the crest of the lip and greatest concavity of the mucobuccal fold or the distance between the corional border of the attached gingiva and the mucobuccal fold could be measured [7].

The term mucogingival surgeries were introduced by Freidman and Levin in 1957, to describe the surgical procedure that corrects the relationship between the gingival and oral mucous membrane such as attached gingiva, shallow vestibule, and aberrant frenum

\section{*Corresponding Author:}

Dr. Jeevitha,

Senior Lecturer, Department of Periodontics, Saveetha Dental College and Hospitals, Saveetha Institute Of Medical And Technical Sciences, Saveetha University, Chennai, India. Tel: $+91-7904613787$

E-mail: jeevitham.sdc@saveetha.com

Received: July 15, 2019

Accepted: August 08, 2019

Published: August 18, 2019

Citation: Lakshya Rani.S, Jeevitha, G.Maragathavalli. Evaluation of Oral Hygiene Status in Patients with Shallow Vestibular Depth in A Hospital Setting - A Retrospective Analysis. Int J Dentistry Oral Sci. 2019;S8:02:0011:56-60. doi: http://dx.doi.org/10.19070/2377-8075-SI02-080011

Copyright: Jeevitha ${ }^{\circ} 2019$. This is an open-access article distributed under the terms of the Creative Commons Attribution License, which permits unrestricted use, distribution and reproduction in any medium, provided the original author and source are credited. 
[8]. In 1953, Goldman emphasized that a shallow vestibule leads to food impaction against the gingival margin and into the interproximal spaces, which makes it difficult for the patient to clean the area [9]. However, the aim of this study is to evaluate the oral hygiene status in patients with shallow depth.

\section{Materials and Methods}

\section{Study Setting and Sampling}

This study is a single- centred retrospective study, carried out in a private dental college. The present study was approved by Institutional ethical committee [IEC] (Ethical approval number: SDC/ SIHEC/2020/DIASDATA/0619-0320) and was in accordance with the ethical standards that were stipulated. All available records of patients with shallow vestibular depth from June 2019 - April 2020 were examined and included in our data collection. A total of 86000 case sheets were reviewed. Cross verification of data for error was done by presence of additional reviewers and by photographic evaluation. Two examiners were involved in the study.

\section{Data Collection}

Acquisition of data was done from the hospital database which records all patient details. The study included 15 patients with shallow vestibular depth. The collected data were grouped based on the presence of shallow vestibular depth. Gender was categorised into males and females and age was categorised into 18-35 years, 36-55 years and $>55$ years. The data were entered in the system in a methodical manner. For this study, data regarding age, gender and the oral hygiene index- simplified interpretation were collected. The data was then entered in excel manually and imported to SPSS for analysis. Incomplete or censored data were excluded from the study.

\section{Statistical Analysis}

The statistical analysis was done using SPSS software (SPSS version 21.0, SPSS, Chicago II, USA). Descriptive statistics was used to summarise the demographic information of the patients included in this study. Descriptive statistics is used for the acquisition of frequency distribution of the data. Chi-square test was applied to analyse the association of different variables. Statistical significance was kept at $\mathrm{p}<0.05$.

\section{Results and Discussion}

In the present study, based on the age wise distribution of study population, $50 \%$ of patients were found in the age group of 3655 years, $28.5 \%$ of the population was found in the age group of $>55$ years and $21.4 \%$ of the population was found in the age group of 18-35 years with shallow vestibular depth (Figure $1)$. Based on the gender wise distribution of study population, females $(64.2 \%)$ dominated the study population than males $(35.7 \%$ ) (Figure 2). Based on the OHI-S score of the study population, the oral hygiene status was found to be fair in $57.1 \%$ of the patients, good in $24.3 \%$ of the patients and poor in $24.3 \%$ of the patients (Figure 3).

Based on the association of age and OHI-S, $14 \%$ of the patients had good, $28 \%$ of the patients had fair and $7 \%$ of the patients had poor oral hygiene status in the age group between 18-35 years and $7 \%$ of the patients had good, $28 \%$ of the patients had fair and $7 \%$ of the patients had poor oral hygiene status in the age group between $36-55$ years. (Figure 4)

Based on the association of gender and OHI-S, 7\% of the patients had good, $21 \%$ of the patients had fair and $7 \%$ of the patients had poor oral hygiene status among males and $14 \%$ of the patients had good, $36 \%$ of the patients had fair and $14 \%$ of the patients had poor oral hygiene status among females (Figure 5).

Several studies indicated that the role of adequate width of attached gingiva is very important for the maintenance of oral hygiene. Shallow vestibule may occur without any symptoms, but this may explore the patient due to unesthetics appearance, difficulty to perform plaque control procedures, dentinal hypersensitivity, etc.,[1] Several studies indicated that the role of adequate depth of vestibule is very important for the maintenance of oral hygiene. Wennstrom and PiniPrato reported that combination of the shallow vestibule and inadequate width of attached gingiva might favor the food accumulation during mastication and difficulty to maintain the oral hygiene [10].

The prevalence of Shallow vestibular depth in this study was found in $50 \%$ of the population in both the age groups of 18 - 35 years and 36-55 years. This prevalence is compared with studies

Figure 1. Bar chart represents the distribution of the study population by age. The $X$ axis denotes the age group of the patients and the $\mathrm{Y}$ axis denotes the percentage of patients with shallow vestibular depth. From the graph, it is observed that the majority of the patients were in the age group of $36-55$ years $(50 \%)$.

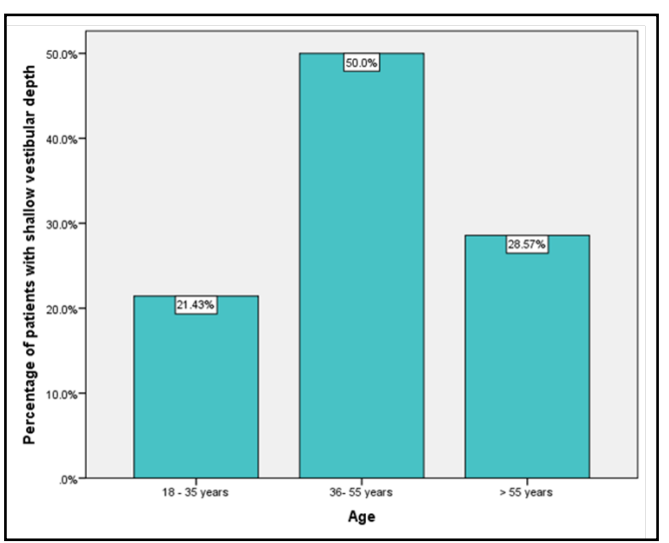


Figure 2. Bar chart represents the distribution of the patients based on gender. The $\mathrm{X}$ axis denotes the gender of the patients and the $\mathrm{Y}$ axis denotes the percentage of patients with shallow vestibular depth. From the graph, it is observed that the majority of the patients were females $(64.2 \%)$ when compared to males $(35.7 \%)$.

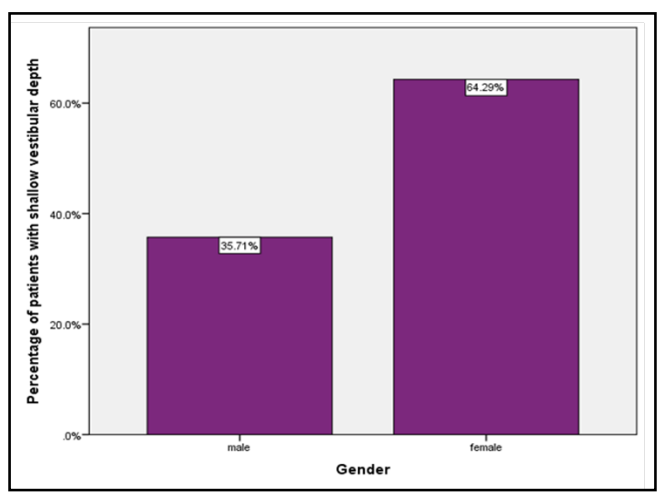

Figure 3. Bar chart represents the OHI-S score of the study population.. The $\mathrm{X}$ axis denotes the OHI-S interpretation and $\mathrm{Y}$ axis denotes the number of patients with shallow vestibular depth. From the graph, it is observed that the majority of the patients were found to have fair $(57.1 \%)$ oral hygiene status.

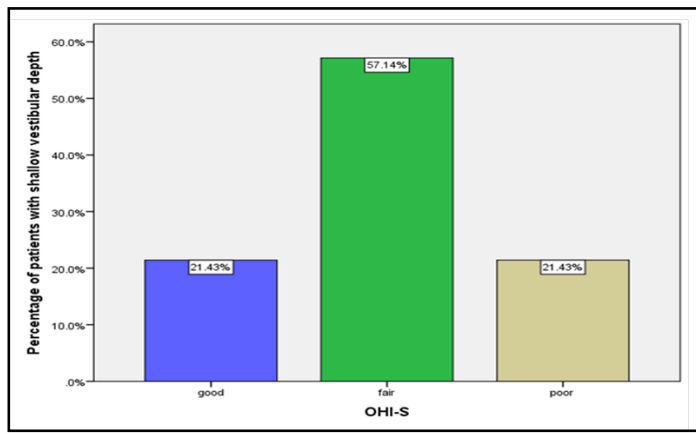

Figure 4. Bar chart represents the association between the age group and OHI-S interpretation. $\mathrm{X}$ axis denotes the age group of the patients and $\mathrm{Y}$ axis denotes the number.The oral hygiene status was found to be fair in the age group between 36-55 years (green;42.8\%) and patients over 55 years of age showed poor oral hygiene(beige). However, it is statistically not significant. (Chi-square test, $\mathrm{p}$ value- 0.068 ( $\mathrm{P}>0.05)$ ).

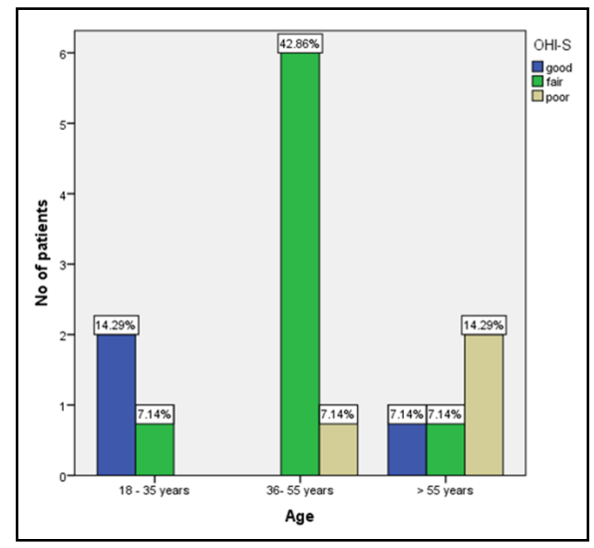

mentioned in a review paper and found to be lower than Vietnamese $(72.5 \%)$, France (84\%) and higher than Malaysia (28.6\%), Sweden (44\%) and India $(24.29 \%)[1,11]$. However the age group was not exactly the same in all these studies. But a research study on Indian population reported a significant association of width of attached gingiva on oral hygiene index [12]. Wade reported that adequate width of attached gingiva is a common requirement for root coverage and suggested vestibular deepening is an effective technique for gaining the width of the attached gingiva and avoiding gingival recession [13].

But it is commonly observed that gingival recession due to shallow vestibular depth is not much in young adults, but it increases with age [14]. In the present study, the oral hygiene status was found to be fair in the majority of the female patients. This is in contrast to the results which reported in Indian, American and Turkey studies $[15,16]$ and is attributed due to less frequency of dental visits, poor oral hygiene and smoking habit in males than females. The mean vestibular depth, measured from the marginal gingiva to mucobuccal fold, was $9.21 \mathrm{~mm}$. In patients with gingival recession either adjacent marginal gingiva level was considered. Ward VJ reported a vestibular depth range of $2.5 \mathrm{~mm}$ to $11.5 \mathrm{~mm}$ using radiographic technique [17]. The techniques to deepen the vestibule in edentulous patients was primarily introduced in 1924 by Kazanjian. Goldman et al introduced the rationale and techniques of mucogingival surgery in 1956 [18].

In a study, 20-40-year-old age group of subjects were included 
Figure 5. Bar chart represents the association between the gender and OHI-S. X axis denotes the gender of the patients and the $\mathrm{Y}$ axis denotes the number of patients with shallow vestibular depth. The oral hygiene status was found to be fair in the majority of the female patients (green ;35.7\%) when compared to male patients. However, it is statistically not significant. (Chi-square test, $\mathrm{p}$ value- 0.987 ( $\mathrm{P}>0.05)$.

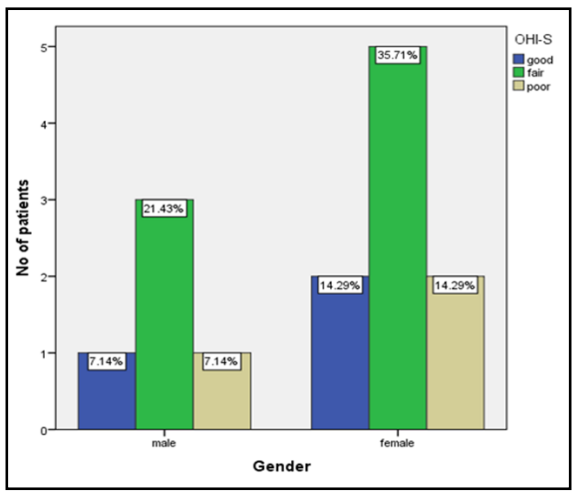

Table 1. Frequency distribution of oral hygiene status in patients with shallow vestibular depth.

\begin{tabular}{|c|c|c|c|c|c|c|c|}
\hline \multirow{2}{*}{$\begin{array}{c}\text { OHI-S } \\
\text { Interpretation }\end{array}$} & \multicolumn{2}{|c|}{$\mathbf{1 8}-\mathbf{3 5}$ years } & \multicolumn{2}{c|}{$\mathbf{3 6} \mathbf{- 5 5}$ years } & \multicolumn{2}{c|}{$>\mathbf{5 5}$ years } & \multirow{2}{*}{ Total } \\
\cline { 2 - 8 } & Males & Females & Males & Females & Males & Females & \\
\hline Good & 1 & 1 & 0 & 0 & 0 & 1 & 3 \\
\hline Fair & 0 & 1 & 3 & 3 & 0 & 1 & 8 \\
\hline Poor & 0 & 0 & 0 & 1 & 1 & 1 & 3 \\
\hline Total & 1 & 2 & 3 & 4 & 1 & 3 & 14 \\
\hline
\end{tabular}

because their permanent dentition was relatively complete and the occurrence of gingival recession and shallow vestibular depth had previously been detected in this age group and can be implied mostly to predisposing factors than chronic periodontal diseases [19]. Previously our team had conducted numerous clinical trials [20-24] and lab studies [25-29] and in vitro studies [30-34] over the past 5 years. Smaller sample size could have impacted the results. For appropriate results, cohort study or community based studies should be done on a larger sample size for the assessment of the oral hygiene status in patients with shallow vestibular depth.

\section{Conclusion}

To conclude, within the limitations of the present study, female patients and patients in the age group of 35- 55 years were comparatively more in the study population. The study showed no significant association of oral hygiene with age and gender in presence of shallow vestibular depth. Until now, the management of shallow vestibule has largely been considered important only when replacing it with a removable prosthetic system for retentive purposes. The present study revealed that in patients with shallow vestibular depth, fair oral hygiene status was more commonly observed emphasizing the need for preventive therapeutic measures to correct the shallow vestibule, thereby improving the oral health.

\section{Acknowledgement}

This research was supported by saveetha dental college and hospital. We thank the department of Periodontics, Saveetha Dental College for providing insight and expertise that greatly assisted this research.

\section{References}

[1]. Kassab MM, Cohen RE. The etiology and prevalence of gingival recession. J Am Dent Assoc. 2003 Feb; 134(2): 220-5. PMID: 12636127.

[2]. Friedman N, Levine HL. Mucogingival surgery: current status. The Journal of Periodontology. 1964 Jan; 35(1): 5-21.

[3]. Goldman HM. Periodontia; A Study of the Histology, Physiology, and Pathology of the Periodontium and the Treatment of its Diseases. Mosby; 1953.

[4]. Padmini H, Raja KK, Hoe ZY, Teh YJ, Ting CJ. Correlation of Width of Attached Gingiva, Depth of the Vestibule on Gingival Health and Oral Hygiene Maintenance in Malaysian Young Adults. Journal of Clinical \& Diagnostic Research. 2018 Nov 1; 12(11).

[5]. Paturu DB, Tanguturi SC, Chava VK, Nagarakanti S. Evaluation of prevalence and predisposing factors of gingival recession in non-medical professional students in Nellore district, Andhra Pradesh: A cross-sectional study. Journal of Indian Association of Public Health Dentistry. 2016 Apr 1; 14(2): 144.

[6]. Khan MA, Gupta S, Tripathi AK, Saimbi CS, Chandra D. Vestibular deepening procedure. International Journal of Health \& Allied Sciences. 2016 Jul 1; 5(3): 192.

[7]. Swamy A, Sogi GM, Sudan J, Vedi A, Sharma H. "Assessment of oral health status among teaching and non-teaching employees of Maharishi Markandeshwar (deemed to be University) Mullana Ambala"-A cross-sectional study. Journal of Indian Association of Public Health Dentistry. 2018 Jul 1; 16(3): 203.

[8]. Friedman N. Mucogingival surgery: The apically repositioned flap. The Journal of Periodontology. 1962 Oct; 33(4): 328-40.

[9]. Goldman HM, Cohen DW. Periodontal therapy. CV Mosby Company; 1973.

[10]. Lindhe J. Mucogingival therapy-periodontal plastic surgery. Clinical periodontlogy and implant dentistry. 2003: 588-92.

[11]. Shaju JP, Zade RM. Width of attached gingiva in an Indian population: A descriptive study. Bangladesh Journal of medical science. 2009; 8(3): 64-7.

[12]. Albandar JM, Kingman A. Gingival recession, gingival bleeding, and dental calculus in adults 30 years of age and older in the United States, 1988-1994. J Periodontol. 1999 Jan;70(1):30-43. PMID: 10052768.

[13]. Wade AB. Vestibular deepening by the technique of Edlan and Mejchar. J Periodontal Res. 1969; 4(4): 300-13. PMID: 4244939.

[14]. Hegab M, Alnawawy M. The Prevalence of Gingival Recession in the Egyptian Population. Perio J. 2020 Feb 11; 4(1): 1-0.

[15]. Kasaj A. Etiology and Prevalence of Gingival Recession. Gingival Recession Management. 2018; 19-31.

[16]. Nguyen-Hieu T, Ha Thi BD, Do Thu H, Tran Giao H. Gingival recession associated with predisposing factors in young vietnamese: a pilot study. Oral 
Health Dent Manag. 2012 Sep; 11(3): 134-44. PMID: 22976574.

[17]. Ward VJ. A technique of measurement of the depth of the vestibular fornix in the mandibular anterior region. J Periodontol. 1976 Sep; 47(9): 525-30. PMID: 1067407.

[18]. Kazanjian VH. Surgical operations as related to satisfactory dentures. Dent Cosmos. 1924 Apr; 66: 387.

[19]. Bhatia G, Kumar A, Khatri M, Bansal M, Saxena S. Assessment of the width of attached gingiva using different methods in various age groups: A clinical study. J Indian Soc Periodontol. 2015 Mar-Apr; 19(2): 199-202. PMID: 26015672.

[20]. Thamaraiselvan M, Elavarasu S, Thangakumaran S, Gadagi JS, Arthie T. Comparative clinical evaluation of coronally advanced flap with or without platelet rich fibrin membrane in the treatment of isolated gingival recession. J Indian Soc Periodontol. 2015 Jan-Feb; 19(1): 66-71. PMID: 25810596.

[21]. Ramesh A, Varghese SS, Doraiswamy JN, Malaiappan S. Herbs as an antioxidant arsenal for periodontal diseases. J Intercult Ethnopharmacol. 2016 Jan 27;5(1):92-6. PMID: 27069730.

[22]. Varghese SS, Thomas H, Jayakumar ND, Sankari M, Lakshmanan R. Estimation of salivary tumor necrosis factor-alpha in chronic and aggressive periodontitis patients. Contemp Clin Dent. 2015 Sep;6(Suppl 1):S152-6. PMID: 26604566

[23]. Avinash K, Malaippan S, Dooraiswamy JN. Methods of Isolation and Characterization of Stem Cells from Different Regions of Oral Cavity Using Markers: A Systematic Review. Int J Stem Cells. 2017 May 30; 10(1): 12-20. PMID: 28531913

[24]. Panda S, Jayakumar ND, Sankari M, Varghese SS, Kumar DS. Platelet rich fibrin and xenograft in treatment of intrabony defect. Contemp Clin Dent. 2014 Oct; 5(4): 550-4. PMID: 25395778.

[25]. Mootha A, Malaiappan S, Jayakumar ND, Varghese SS, Toby Thomas J. The Effect of Periodontitis on Expression of Interleukin-21: A Systematic Review. Int J Inflam. 2016; 2016: 3507503. PMID: 26998377.

[26]. Ravi S, Malaiappan S, Varghese S, Jayakumar ND, Prakasam G. Additive Effect of Plasma Rich in Growth Factors With Guided Tissue Regeneration in Treatment of Intrabony Defects in Patients With Chronic Periodontitis: A Split-Mouth Randomized Controlled Clinical Trial. J Periodontol. 2017 Sep; 88(9): 839-845. PMID: 28474968.

[27]. Khalid W, Varghese SS, Sankari M, Jayakumar ND. Comparison of Serum Levels of Endothelin-1 in Chronic Periodontitis Patients Before and After Treatment. J Clin Diagn Res. 2017 Apr; 11(4): ZC78-ZC81. PMID: 28571268.

[28]. Khalid W, Vargheese SS, Lakshmanan R, Sankari M, Jayakumar ND. Role of endothelin-1 in periodontal diseases: A structured review. Indian J Dent Res. 2016 May-Jun; 27(3): 323-33. PMID: 27411664.

[29]. Ramesh A, Varghese SS, Jayakumar ND, Malaiappan S. Chronic obstructive pulmonary disease and periodontitis-unwinding their linking mechanisms. journal of oral biosciences. $2016 \mathrm{Feb}$ 1; 58(1): 23-6.

[30]. Kavarthapu A, Thamaraiselvan M. Assessing the variation in course and position of inferior alveolar nerve among south Indian population: A cone beam computed tomographic study. Indian J Dent Res. 2018 Jul-Aug; 29(4): $405-$ 409. PMID: 30127186.

[31]. Jangid K, Ramamurthy J, Mathew V, et al. Anti-cytokine therapy in periodontitis. Res J Pharm Biol Chem Sci. 2015; 6: 372-376.

[32]. Ramesh A, Vellayappan R, Ravi S, Gurumoorthy K. Esthetic lip repositioning: A cosmetic approach for correction of gummy smile - A case series. J Indian Soc Periodontol. 2019 May-Jun; 23(3): 290-294. PMID: 31143013.

[33]. Priyanka S, Kaarthikeyan G, Nadathur JD, Mohanraj A, Kavarthapu A. Detection of cytomegalovirus, Epstein-Barr virus, and Torque Teno virus in subgingival and atheromatous plaques of cardiac patients with chronic periodontitis. J Indian Soc Periodontol. 2017 Nov-Dec; 21(6): 456-460. PMID: 29551863.

[34]. Gajendran PL, Parthasarathy H, Tadepalli A. Comparative evaluation of cathepsin $\mathrm{K}$ levels in gingival crevicular fluid among smoking and nonsmoking patients with chronic periodontitis. Indian J Dent Res. 2018 Sep-Oct; 29(5): 588-593. PMID: 30409937 